\title{
D-GLİKOZDAN D-SORBİTOL VE L-ASKORBİK ASİT ÜRETİMİ: BU BİLEŞİKLERİN ÖZELLİKLERİ, KULLANIM ALANLARI VE SAĞLIK ÜZERİNE ETKİLERİ
}

\author{
Ceren Mutlu ${ }^{1,2^{*}}$, Mustafa Erbaş ${ }^{1}$ \\ ${ }^{1}$ Akdeniz Üniversitesi Mühendislik Fakültesi Gıda Mühendisliği Bölümü, Antalya, Türkiye \\ ${ }^{2}$ Balıkesir Üniversitesi Mühendislik Fakültesi Gıda Mühendisliği Bölümü, Balıkesir, Türkiye
}

Geliş / Received: 06.08.2019; Kabul / Accepted: 09.12.2019; Online bask1 / Published online: 21.01.2020

Mutlu, C., Erbaş, M. (2020). D-glikozdan D-sorbitol ve L-askorbik asit üretimi: bu bileşiklerin özellikleri, kullanım alanları ve sağlık üzerine etkileri. GID $A$ (2020) 45 (1): 92-102 doi: 10.15237/gida.GD19117

Mutlu, C., Erbaş, M. (2020). Production of D-sorbitol and L-ascorbic acid from D-glucose: their properties, fields of usage and effects on health. GIDA (2020) 45 (1): 92-102 doi: 10.15237/gida.GD19117

\section{Öz}

D-sorbitol birçok meyvede doğal olarak bulunan bir şeker alkolüdür. L-askorbik asit ise bitkiler ve bazı hayvanlar tarafindan sentezlenebilen ancak insanlar tarafindan L-gulono- $\gamma$-lakton oksidaz enzimi eksikliği nedeniyle sentezlenemediği için dışandan alınması zorunlu olan bir bileşiktir. D-sorbitol ve L-askorbik asit gıda, kimya, ilaç ve kozmetik sektörlerinde sıklıkla kullanılan ve insan sağlığı üzerine birçok olumlu etkileri bulunan iki üründür. $\mathrm{Bu}$ ürünler $\mathrm{D}$-glikozdan kimyasal ve biyokimyasal reaksiyonlar ile ticari olarak üretilmektedirler. $\mathrm{Bu}$ bileşiklerin ticari üretiminde genellikle Reichstein-Grüssner veya iki aşamalı fermantasyon yöntemleri kullanılmaktadır. Bu çalışmada D-sorbitol ve L-askorbik asidin bazı özellikleri, kullanım alanları, sağlık üzerine etkileri ve üretim yöntemleri derlenmiştir.

Anahtar kelimeler: D-glikoz, hidrojenizasyon, fermantasyon, Gluconobacter oxydans, Ketogulonicigenum vulgare

\section{PRODUCTION OF D-SORBITOL AND L-ASCORBIC ACID FROM D-GLUCOSE: THEIR PROPERTIES, FIELDS OF USAGE AND EFFECTS ON HEALTH}

\begin{abstract}
$\mathrm{D}$-sorbitol is a sugar alcohol naturally found in many fruits. L-ascorbic acid is a compound that can be synthesized by plants and some animals but must be externally taken by humans because it cannot be synthesized due to the lack of L-gulono- $\gamma$-lactone oxidase enzyme. D-sorbitol and L-ascorbic acid are two ingredients that are frequently used in the food, chemical, pharmaceutical and cosmetic industries and may have a number of positive effects on human health. These ingredients are generally produced commercially from D-glucose by a series of chemical and biochemical reactions. In the commercial production of these compounds, Reichstein-Grüssner or two-step fermentation methods are generally used. In this study; the properties, fields of usage, effects on human health and production methods of $\mathrm{D}$-sorbitol and L-ascorbic acid are reviewed.
\end{abstract}

Keywords: D-glucose, hydrogenation, fermentation, Gluconobacter oxydans, Ketogulonicigenum vulgare

\footnotetext{
* Yazışmalardan sorumlu yazar/ Corresponding author

$\triangle$ cerenmutlu@akdeniz.edu.tr,

(f) (+90) 2423104317 ,

县 $\quad(+90) 2423106306$
}

Ceren Mutlu; ORCID no: 0000-0003-4943-2798

Mustafa Erbaş; ORCID no: 0000-0002-9485-2356 


\section{GİRİ̧}

D-sorbitol ve L-askorbik asit gida, kimya, ilaç ve kozmetik sektörlerinde geniş kullanım alanları bulunan iki ticari üründür. Bu ticari ürünler $\mathrm{D}$ glikoz kullanılarak bir seri kimyasal ve biyokimyasal dönüşüm reaksiyonları dizisi ile üretilmekte ve birçok ülkede pazara sunulmaktadır. Dünyada yıllık D-sorbitol ve Laskorbik asit üretimi sırasıyla yaklaşık 800.000 (Zhang vd., 2016) ve 110.000 ton kadardır (Bhand ve Patwardhan, 2015). Sorbitol, tatlliı̆a ve düşük glisemik indekse sahip olması nedenleriyle diğer şekerlerin yerine gidalara ilave edilmektedir (Deis ve Kearsley, 2012). L-askorbik asit ise sahip olduğu antioksidan özelliği nedeniyle et, süt, meyve-sebze ve yağ ürünlerine katkılanarak gıda sanayinde kullanılmaktadır (Delić vd., 1989). Bu çalışmada D-sorbitol ve L-askorbik asidin genel özellikleri, kullanım alanları, sağlık üzerine etkileri ve üretim yöntemleri derlenmiştir.

\section{Sorbitol ve Özellikleri}

Birçok meyvede (armut, elma, kayısı, şeftali vb.) doğal olarak bulunan sorbitol ilk olarak 1872 yllında üvez ağac1 (Sorbus aucuparia) meyvelerinde keşfedilmiştir. Altı karbonlu bir şeker alkolü olan sorbitolün kimyasal formülü $\mathrm{C}_{6} \mathrm{H}_{14} \mathrm{O}_{6}$ şeklindedir. Sorbitolün molekül ağırllğ1 $182.17 \mathrm{~g} / \mathrm{mol}$, erime noktas1 $93-112^{\circ} \mathrm{C}$ ve suda çözünürlüğü ise 72 $\mathrm{g} / 100 \mathrm{~mL}$ olarak bildirilmiştir (Ghosh ve Sudha, 2012). Sorbitol olarak isimlendirilmesinin yanı sıra D-sorbitol, D-glusitol ve sorbol olarak da adlandırılmaktadır (Grembecka, 2015b). Hoş bir tadı olan ve tüketildiğinde ağızda serinlik hissi veren sorbitolün tatlılığının sakkarozun \%50 ila \%60'1 kadar olduğu bildirilmiştir (Ghosh ve Sudha, 2012). Sorbitolün diğer karbonhidratlarla karşılaştırıldığında tatllığına rağmen daha düşük kalori ve glisemik indeks değerlerine sahip olduğu, kalorisinin $2.7 \mathrm{kcal} / \mathrm{g}$ ve glisemik indeks değerinin ise 9 olduğu bildirilmiştir (Grembecka, 2015b).

\section{Sorbitolün Kullanım Alanları}

Sorbitol ticari olarak şurup veya kristal halinde üretilmekte olup (Mishra vd., 2014), dünyada y1llık üretimi yaklaş1k olarak 800.000 ton kadardır (Zhang vd., 2016). Üretilen sorbitolün \%25 kadar1 L-askorbik asit üretiminde hammadde olarak kullanılırken, \%25 kadarı ise şeker şurubu üretiminde değerlendirilmektedir. Sorbitolün geriye kalan \%50 kadarından ise kimya, ilaç ve kozmetik sektörlerinde farklı amaçlarla yararlanılmaktadır (Mishra vd., 2014). Gida sektöründe kullanılan sorbitolün şurup ve toz kristalleri E420 koduyla ifade edilmekte olup, GRAS (Generally Recognised As Safe) listesinde bulunan katkı maddeleri arasında yer almaktadır (Deis ve Kearsley, 2012). Sorbitol, kalori ve glisemik indeks değerlerinin mono ve disakkaritlere göre daha düşük olması nedeniyle diyet ve diyabetik gidalarda diğer tatlandırıcılarla birlikte istenilen aroma ve tatllliğ1 ayarlamaya yardımcı olarak kullanılmaktadır. Ayrıca bu özelliği nedeniyle gıdalara ilave edilmesinin yanı sıra tabletler halinde de üretilerek satışa sunulmaktadır.

Sorbitol, tatlılık verici özelliğinin yanı sıra gıdalarda nem çekici, hacim ve kıvam arttırıcı ve stabilizatör olarak da değerlendirilmektedir (Grembecka, 2015b). İşlenmiş et ürünlerinin lezzetini geliştirmek ve pişme sirasında mevcut şeklin korunması amaciyla plastikleştirici ajan olarak da bu gibi ürünlere ilave edilmektedir. Ayrıca bu ürünlerde sorbitolün sıcaklık etkisi ile esmerleşmemesi son ürün kalitesi bakımından önemli bir avantajdır (Deis ve Kearsley, 2012). Fırınlanmış ürünlere ve kahvaltılik gevreklere uzun yıllardır ilave edilen sorbitol, higroskopik özelliği nedeniyle ürünün nem içeriğinin sabit tutulması ve raf ömrünün daha uzun olması amaçlarıyla kullanılmaktadır (Ghosh ve Sudha, 2012). Sorbitol sakızlarda plastiğe benzer bir tekstür oluşturarak sakızın nemli bir şekilde kalmasını sağlamakta ve kalıp halinde kurumasını engellemektedir. Bunların yanı sira ekzotermik olarak çözündüğünden ağızda bir ferahlık hissi de oluşturmaktadır (Deis ve Kearsley, 2012).

Sorbitol gıdaların içeriğgine ilave edilmekle birlikte; gida ambalajlarında da ambalajların fiziksel özelliklerini geliştirmek amacıyla plastikleştirici ajan olarak kullanılmaktadır (Sanyang vd., 2015; Kowalczyk vd., 2016; Ma vd., 2018). Sorbitol ayrıca polimer ve ilaç sanayilerinde kullanılan sorbitan veya izosorbidin (Robinson vd., 2015; Zada vd., 2017) yanı sıra çeşitli düşük molekül ağırlıklı alkollerin ve parafin gibi ürünlerin 
sentezinde hammadde olarak da değerlendirilmektedir (García vd., 2019).

\section{Sorbitolün İnsan Sağlığı Üzerine Etkileri}

Gıda sanayi, özellikle biyolojik çalışmaların artışı, insanların yaşam tarzlarındaki değişim ve gıda tüketimi ile ilgili sağlıklı beslenme bilincinin yaygınlığına bağlı olarak üretimde sağlık kaygisını daha fazla göz önünde bulundurmaktadır. Yüksek miktarda şeker tüketiminin diyabet ve obezite gibi hastalıkların artışına neden olduğu bilinen bir gerçektir. $\mathrm{Bu}$ hastalıkların önlenmesi veya azaltılması amaciyla gida sektöründe alternatif tatlandırıcı madde arayışı sonucu sakkaroz, glikoz ve fruktoz gibi diğer ticari karbonhidratların yerine şeker alkolleri kullanılmaya başlanmıştır (Deis ve Kearsley, 2012; Grembecka 2015b). Şeker alkollerinden biri olan sorbitol, sakkaroza ve diğer karbonhidratlara göre çeşitli sağlık avantajlarına sahiptir (Grembecka, 2015b). Sorbitol, reaktif aldehit ve keton gruplarını içermediğinden Maillard reaksiyonuna katılamamakta (Ghosh ve Sudha, 2012) ve bu nedenle 1sil işlem uygulanan ürünlerde sağlığ1 olumsuz etkileyen hidroksimetilfurfural (HMF) gibi ürünlerin oluşumu da gerçekleşmemektedir (Fennema vd., 2008).

Sorbitol, düşük glisemik indekse sahip olması nedeniyle vücut ağırlığının düzenlenmesi ve kilo kaybına yardımcı olması bakımlarından diğer şekerlerin yerine gidalara ilave edilmektedir (Deis ve Kearsley, 2012). Ayrica kanda glikoz seviyesini arttırmadığından ve metabolik sindirimi için çok az düzeyde insüline ihtiyaç bulunduğundan diyabet hastalığına sahip kişiler için önemli bir tatlandırıcı kaynağıdır (Ghosh ve Sudha, 2012).

Ağız içerisinde bulunan mikroorganizmalar şekerleri parçalayarak asit oluşumuna neden olmakta ve diş yüzeyindeki $\mathrm{pH}$ değerini 5.7'nin altına düşürdüğünde ise diş minesinde dekalsifikasyon meydana getirerek (Deis ve Kearsley, 2012) ağız ve diş sağllğını olumsuz etkilemektedir (Grembecka, 2015b). Sorbitol ise birçok karbonhidrattan farklı olarak ağız içerisinde ve dişlerde bulunan mikroorganizmalar tarafından metabolize edilemediğinden ağız ve diş sağlığ1 bakımından bir tehdit oluşturmamaktadır (Grembecka, 2015a).

Yapılan araştırmalarda sorbitolün demirle kompleks oluşturarak gastrointestinal sistemde demirin çözünürlüğünü ve böylece emilimini arttırdığı bildirilmiştir. Ayrıca sorbitolün vitamin sentezi yapan bağırsak mikroflorasının gelişimini destekleyerek de vücutta $B_{12}$ vitamini sentezini ve emilimini arttırdığ1 da rapor edilmiştir (Ghosh ve Sudha, 2012). Ayrıca şeker alkollerinin prebiyotik bileşenlere benzer etkiler gösterdiği ve bağırsak fonksiyonlarının düzenlenmesine yardımcı olduğu da rapor edilmiştir. Sorbitol için sağlık açısından yasal olarak sınırlandırılmış bir günlük tüketim limiti bulunmamakla birlikte, Amerikan Gıda ve İlaç Kurumu tarafindan insanlar için kabul edilebilir günlük maksimum sorbitol alım miktarı $50 \mathrm{~g}$ olarak önerilmiştir (Sheet vd., 2014). Ancak diğer şeker alkollerinde de olduğu gibi önerilen miktarların üzerindeki tüketimi laksatif etki, şişkinlik ve karın ağrısı gibi rahatsızlıklara neden olmaktadır (Grembecka, 2015a). Bu rahatsızlikların görülme sıklığının ve şiddetinin şeker alkolü tüketim miktarı ve süresi ile ortaya çıan adaptasyona bağlı olarak azaldığ1 bildirilmiştir (Deis ve Kearsley, 2012).

\section{L-Askorbik Asit ve Özellikleri}

L-askorbik asit bitkiler ve bazı hayvanlar tarafindan sentezlenebilen, ancak insanlar tarafindan L-gulono- $\gamma$-lakton oksidaz enzimi eksikliği nedeniyle sentezlenemeyen (Delić vd., 1989) ve vücuttaki metabolik fonksiyonların devamlılığı için dışarıdan alınması zorunlu olan bir bileşiktir (Bhand ve Patwardhan, 2015; Padayatty ve Levine, 2016). L-askorbik asit ilk olarak 1928 yılında böbrek üstü bezlerinden izole edilerek kristal hekzo-uronik asit adıyla tanımlanmış ve daha sonra ise bitki dokularında tespit edilmiştir (del Rocío Gómez-García ve Ochoa-Alejo, 2016). L-askorbik asidin $\mathrm{C}$ vitamini olarak adlandırilması ise 1965 yllinda IUPAC-IUB komisyonu tarafından tavsiye edilmiştir (Vandamme, 2016).

L-askorbik asit beyaz-sarı renkte ve kristal katı formdadır (Delić vd., 1989). Kimyasal formülü $\mathrm{C}_{6} \mathrm{H}_{8} \mathrm{O}_{6}$ olup, molekül ağırllğı $176.13 \mathrm{~g} / \mathrm{mol}$, erime noktas $190-192^{\circ} \mathrm{C}$ (Vandamme, 2016) ve 
suda çözünürlüğü ise $30 \mathrm{~g} / 100 \mathrm{~mL}$ olarak bildirilmiştir (Eitenmiller vd., 2016). Oksijene karşı hassas olan L-askorbik asit, kristal formda veya düşük su aktivitesine sahip ortamda bulunduğunda oksijen varllğında dahi yüksek stabilite gösterebilmektedir. Ancak yüksek su aktiviteli bir ortamda bulunduğunda ise hızla okside olarak dehidroaskorbik aside dönüşmektedir. Dehidroaskorbik asit de daha düşük olmakla birlikte L-askorbik asit gibi biyolojik aktivite göstermekte olup, oksidasyonun ileri aşamalarında biyolojik aktivitesi bulunmayan 2,3-diketo-L-gulonik asit bileşiğine dönüşmektedir. Biyolojik sistemlerde indirgeyici ajanlar ile dehidroaskorbik asit formu L-askorbik aside geri dönüştürülebilirken, 2,3-diketo-L-gulonik asit bileşiği ise geri dönüşümsüz olarak kalmaktadır. Oksijenin yanı sıra sıcaklık, 1şık, pH ve metal katalizörler de L-askorbik asit stabilitesi üzerine etki etmektedir (Eitenmiller vd., 2016). L-askorbik asit 1şık varlığında ve yüksek sıcaklıkta $\mathrm{Fe}^{+3}$ ve $\mathrm{Cu}^{+2}$ katalizörlüğünde kolaylıkla okside olmaktadır (Vandamme, 2016).

\section{L-Askorbik Asidin Kullanım Alanları}

L-askorbik asit çoğunlukla ilaç, gıda, içecek, yem ve kozmetik sanayilerinde kullanılmakta olup (Zhou vd., 2012; Pappenberger ve Hohmann, 2013; Bhand ve Patwardhan, 2015; Vandamme, 2016), dünyada yıllık üretim miktarı yaklaşık olarak 110.000 tondur (Bhand ve Patwardhan, 2015). Üretilen L-askorbik asidin önemli bir kısm1 ilaç sanayinde değerlendirilmektedir. L-askorbik asit, iskorbit hastalığının yanı sıra çeşitli patolojik durumların önlenmesi ve tedavisi için kullanılmakta ve metabolik fonksiyonların sağlıklı bir şekilde sürdürülebilmesini sağlamaktadır. Laskorbik asit bazı anemi türlerinin ve kardiyovasküler hastalıkların tedavisine ve yaraların iyileştirilmesine yardımcı olmaktadır. Bağışıklık sistemine yönelik uyarıcı rolünden dolayı soğuk algınlı̆̆1, grip vb. gibi çeşitli enfeksiyonların önlenmesinde de L-askorbik asit takviyesinden yararlanılmaktadır (Vandamme, 2016).

L-askorbik asit sahip olduğu antioksidan özelliği nedeniyle gida sektöründe geniş bir uygulama alanına sahiptir. Sıv1 ve katı yağlara, et ve süt ürünlerine, konserve ve dondurulmuş gidalara ve içeceklere antioksidan madde olarak ilave edilmektedir. Ayrica L-askorbik asit unlara da ilave edilerek hamurlarda yapı düzenleyicisi olarak kullanılmaktadır (Delić vd., 1989). L-askorbik asit ilavesi ile gidalarda oksidasyon ve esmerleşme reaksiyonlar1 engellenerek, aroma ve renkte istenilmeyen değişimler azaltılabilmekte veya önlenebilmektedir. İçecek endüstrisinde ise belirtilen özelliklerinin yanı sıra antiseptik koruma sağlaması sebebiyle önemli bir katkı maddesi olarak değerlendirilmektedir.

Yem sanayisi hayvanların; strese karşı yeteneklerini arttırmak, bağışıklık fonksiyonlarını geliştirmek, kemik gelişimini hızlandırmak ve üreme yeteneklerini arttırmak gibi amaçlarla yemlere L-askorbik asit ilavesi yapmaktadır. Kozmetik ürünlere ise deride oluşan pigmentlerin önlenmesi, serbest radikallerin parçalanması ve yaşlanma belirtilerinin geciktirilmesi gibi amaçlarla L-askorbik asit katkılaması yapılmaktadır (Zhou vd., 2012).

\section{L-Askorbik Asidin İnsan Sağlı̆̆ı Üzerine Etkileri}

İskorbit, otoimmün idiopatik trombositopenik purpura, yeni doğan bebeklerde hipoksik-iskemik beyin hasar1, viral miyokarditler, kronik ve akut viral hepatit, askaris, gastrointestinal kanal ülseri, damar setliği, kornea yanması ve konjonktivit, grip, kanser, bronşiyal astım ve nitrit zehirlenmesi gibi sağlık sorunlarının engellenmesinde ve tedavisinde L-askorbik asit kullanılmaktadır (Zhou vd., 2012). L-askorbik asit ökaryot hücre yapısına sahip canlıların hidroksilasyon reaksiyonları gibi metabolik faaliyetlerinde enzim kofaktörü olarak önemli rol oynamaktadır (Canali vd., 2014). Prolin aminoasidi ve kolajen sentezinde kullanılan lisinin hidroksilasyonunda görev alan prolil-3hidrolaz, prolil-4-hidrolaz ve lisil hidrolaz enzimlerinin aktiviteleri için metabolizmada Laskorbik asit gereksinimi bulunmaktadir. ATP üretiminde yağ asitlerinin mitokondriye taşınması için gerekli olan karnitin bileşiğinin sentezinden sorumlu olan $\varepsilon$-N-trimetil-L-lisin hidrolaz ve $\gamma$ butirobetain hidrolaz enzimlerinin faaliyetleri için de L-askorbik aside ihtiyaç duyulmaktadır (Vandamme, 2016). L-askorbik asit histonlar ve 
nükleik asitlerin demetilasyonuna katk1 sağlamaktadır (Camarena vd., 2016). Ayrica mikrozom metabolizmasında, nörotransmitterlerin sentezinde ve tirozin sentezi ve katabolizmasında yer almaktadır. Antioksidan özelliği nedeniyle demir ve bakır atomlarının indirgenmiş hallerinin korunarak, oksidasyonlarının önlemesine katkı sağlamaktadır (Vandamme, 2016). Ayrıca bu özelliği ile vücutta sağlık problemlerine neden olan ve metabolik faaliyetler sonucu oluşan hidrojen peroksit $\left(\mathrm{H}_{2} \mathrm{O}_{2}\right)$ gibi reaktif oksijen türlerine ve birçok serbest radikale karşı korunmaya yardımcı olmaktadır (Sies, 2014; Wheeler vd., 2015). Askorbik asit beyindeki oksidasyon-redüksiyon mekanizmasında da rol almakta ve eksikliğinın meydana gelen redoks dengesizliği ve oksidatif strese bağlı olarak Alzheimer ve Parkinson gibi sağlık sorunlarının ortaya çımasıyla ilişkisinin bulunduğu belirtilmektedir (Covarrubias-Pinto vd., 2015).

Sağlık açısından faydalı özelliklerinin yanı sıra aç olarak yüksek dozda L-askorbik asit tüketildiğinde hazımsızlık ve ishal gibi sorunların ortaya çıkabileceği bildirilmiştir. Ayrıca aşırı tüketimin, demir yükünü arttırdığ1 ve böbrek taş1 oluşumuna neden olduğu da rapor edilmiştir (Thomas vd., 2013). İnsanlarda günlük yaklaşık olarak $60 \mathrm{mg} \mathrm{L-}$ askorbik asidin metabolik faaliyetler sirasında parçalandığ1 belirlenmiştir. Organizma iç ortamında normal dengelerin ve sağllğın korunması için günlük L-askorbik asit tüketim miktarının kadınlarda $70 \mathrm{mg}$ ve erkeklerde ise 90 mg kadar olması gerektiği rapor edilmiştir (Knight vd., 2016).

\section{D-Glikozdan D-Sorbitol ve L-Askorbik Asit Üretimi}

Askorbik asidin keşfinden sonra saf L-askorbik asit ihtiyacı ortaya çıkmış ve bu durum 1930'lu yılların başında ticari olarak L-askorbik asit üretim proseslerinin araştırılması için çalışmaların başlamasına yol açmıştır (Pappenberger ve Hohmann, 2013; Vandamme, 2016). 1933-1934 y1lar1 arasinda Tadeus Reichstein ve Anton Grüssner isimli bilim adamları tarafindan Laskorbik asit üretimi gerçekleştirilmiştir (Vandamme, 2016). Günümüzde ReichsteinGrüssner prosesi olarak bilinen bu yöntem ile ticari olarak L-askorbik asit üretimi gerçekleştirilmektedir. Ayrıca bu yöntem dışında iki aşamalı fermantasyon yöntemi de L-asorbik asidin öncü maddesi olan 2-keto-L-gulonik asit (2KLG) üretimi için kullanılmaktadır (Zhou vd., 2012).

\section{Reichstein-Grüssner Yöntemi ile D-Sorbitol ve L-Askorbik Asit Üretimi}

Reichstein-Grüssner yöntemi, bir seri kimyasal ve mikrobiyal basamaktan oluşmaktadır (Zhou vd., 2012). Bu yöntem ile L-askorbik asit üretim süresi üç gün ve verim ise yaklaşı $\% 55$ kadardır (Bommarius ve Riebel-Bommarius, 2004). Proses sırasında, D-glikozun hidrojenizasyon ile Dsorbitole dönüştürülmesi ve ilerleyen aşamalarda ise L-askorbik asit üretimi gerçekleştirildiğinden tek bir yöntem ile iki farklı ticari ürün elde edilebilmektedir. L-askorbik asit üretim basamakları ve oluşan moleküller Şekil 1'de verilmişsir.

Yöntemin ilk basamağında yüksek sıcaklık (140$\left.150^{\circ} \mathrm{C}\right)$ ve basınç $(80-125$ bar) altında D-glikozun aldehit grubunun hidrojenizasyon ile sorbitole dönüştürülmesi işlemi yer almaktadır. Hidrojenizasyon ile monosakkaritlerde bulunan aldehit veya keton grupları hidrojen ile doyurulmakta ve alkol grupları oluşturulmaktadır (Deis ve Kearsley, 2012). Karbonhidratların hidrojenizasyonu gida kimyası çalışmalarının temel proseslerinden birisidir ve sorbitol üretimi için yapılan ilk hidrojenizasyon işleminde, D-glikoz bileşiği Raney-nikel (Ni) katalizörü kullanılarak sorbitole dönüştürülmüsstür. Ancak daha sonra yapılan araştırmalarda elde edilen ürünlerde nikel kalıntısı tespit edilmiş ve hidrojenizasyon işlemi için nikelin katalitik aktivitesi ve stabilitesinin yeterli olmadığ bildirilmiştir (Zhang vd., 2013; Murzin vd., 2015). Bu nedenlerle sonraki çalışmalarda, Raney-nikel diğer elementler ile kombine edilmiş (Romero vd., 2017) veya doğrudan nikel yerine katalizör olarak rutenyum (Ru) (Guo vd., 2014; Wang vd., 2015; Sulman vd., 2016) ve platin (Pt) (Kobayashi vd., 2014; Lazaridis vd., 2015; Yamaguchi vd., 2016) gibi elementler de kullanılmıştır. Ayrıca sorbitol üretimi için çeşitli çalışmalarda D-glikoz yerine fruktoz şurubu, çeşitli oligosakkaritler, nişasta ve selüloz da 
hammadde olarak denenmiştir (Deis ve Kearsley, 2012; Negahdar vd., 2015; Romero vd., 2016; Yamaguchi vd., 2016).
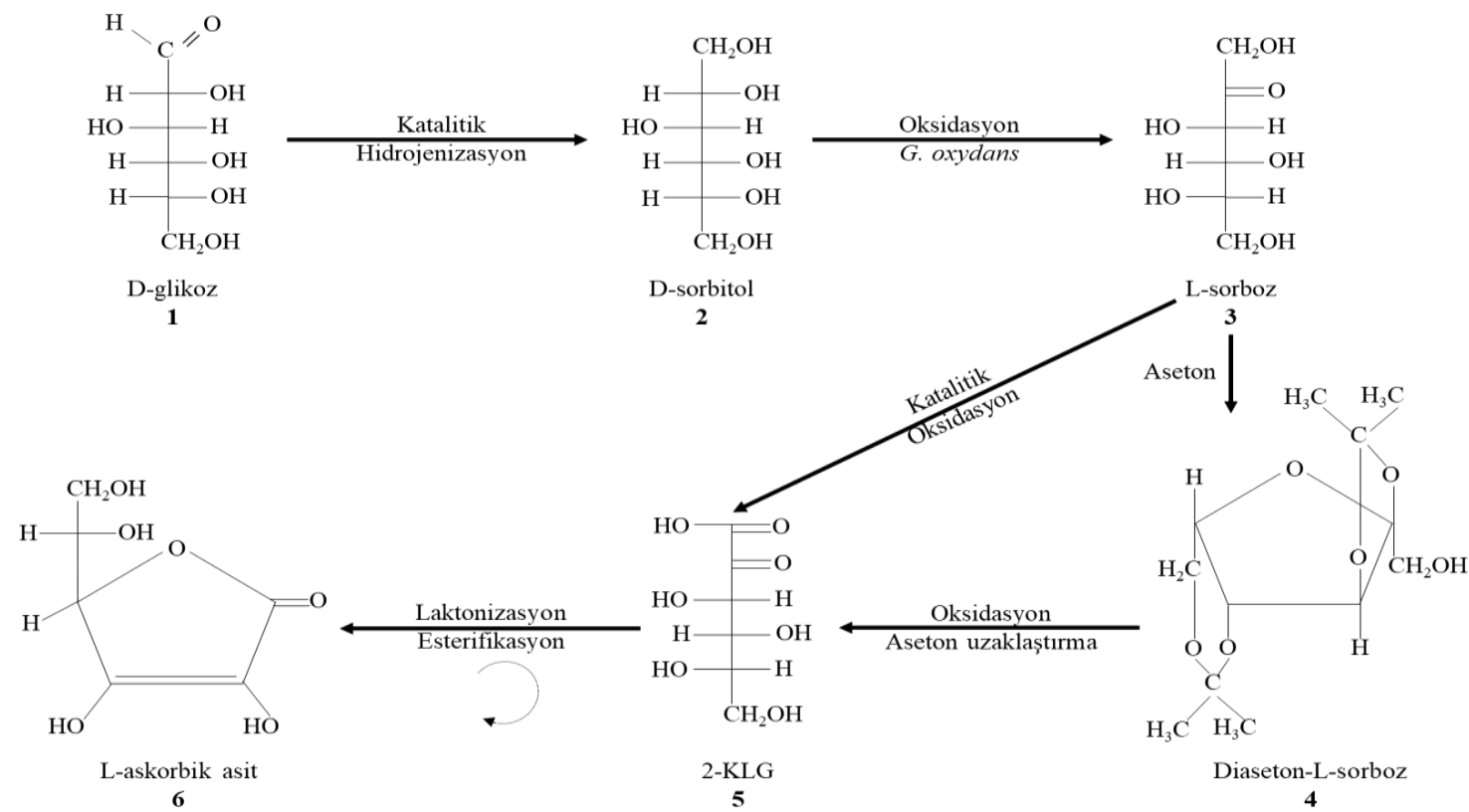

Şekil 1. L-askorbik asit üretim basamakları ve oluşan moleküller

Reichstein-Grüssner prosesinde hidrojenizasyon işlemi için D-glikoz çözeltisi katı katalizörü içeren kolon reaktörüne yüksek basınçlı bir pompa yardımıyla enjekte edilmektedir. Katalizör, reaktör içerisinde amorf bir materyale tutturulmuş ve sabit bir halde bulunmaktadır. D-glikoz ve sisteme beslenen hidrojen, katalizör yüzeyinden geçirilmekte ve uygulanan yüksek sıcaklık ve basınç altında reaksiyona girmektedir (Vandamme, 2016). Yaklaşık iki saatlik bir reaksiyon süresi sonunda $\mathrm{D}$-sorbitol oluşmakta ve elde edilen ürün filtre edildikten sonra aktif karbondan geçirilerek rengi giderilmekte, iyon değişim reçineleri kullanılarak saflaştırılmakta ve evapore edilerek şurup halinde veya püskürterek kurutma uygulanarak toz halinde ticari bir ürüne dönüştürülmektedir (Bommarius ve RiebelBommarius, 2004).

Prosesin ikinci basamağ1 üretilen D-sorbitolün mikrobiyal fermantasyon yoluyla L-sorboza okside edilmesinden oluşmaktadır. Biyolojik oksidasyon için Gluconobacter oxydans mikroorganizması kullanılmakta ve sorbitolün oksidasyonu mikroorganizmada bulunan sorbitol dehidrojenaz enzimi ile gerçekleştirilmektedir (Vandamme, 2016). D-sorbitol G. oxydans tarafindan $30^{\circ} \mathrm{C}$ sicaklık ve $\mathrm{pH}$ değeri 5-6 olarak ayarlanmış bir ortamda yaklaşık 24 saat süre sonunda (Bommarius ve Riebel-Bommarius, 2004) L-sorboza okside edilmektedir (Vandamme, 2016). Elde edilen ürün filtre edilerek, anyon ve katyon iyon değiştirme reçineleri içeren kolonlardan geçirildikten sonra buharlaştırılarak konsantre edilmekte ve kristalizasyon işleminden sonra ticari bir ürüne dönüştürülmektedir (Delić vd., 1989).

Prosesin üçüncü basamağında L-sorboz bileşiğinde bulunan hidroksil gruplarının korunmasi amaciyla ortama aseton ilave edilmekte ve diaseton-L-sorboz bileşiği oluşturulmaktadır (Pappenberger ve Hohmann, 2013; Vandamme, 2016). Bu işlem 24 saat boyunca L-sorboz, aseton, sülfürik asit ve eter çözeltilerinin $30^{\circ} \mathrm{C}$ sıcaklıkta birlikte 1sıtılması ile gerçekleştirilmektedir. Daha sonra elde edilen karışım filtre edilmekte ve kullanılan çözeltiler vakum distilasyon işlemi ile 
uzaklaştırılmaktadır. Bu işlemlerden sonra oluşan diaseton-L-sorboz bileşiği diğer bileşenlerden ayrılarak saflaştırılmaktadır (Bommarius ve Riebel-Bommarius, 2004).

Prosesin dördüncü basamağ1 diaseton-L-sorboz molekülünün potasyum permanganat katalizörlüğünde okside edilerek diaseton-2-ketoL-gulonik aside dönüştürülmesinden oluşmaktadir (Pappenberger ve Hohmann, 2013). Elde edilen diaseton-2-keto-L-gulonik asit, asetondan ayrilarak 2-KLG bileşiğine hidroliz edilmekte ve yapılan çöktürme ve süzme işlemlerinden sonra kurutularak kristalize 2-KLG üretilmektedir.

Daha sonraki çalışmalarda üçüncü basamakta gerçekleştirilen L-sorbozun hidroksil gruplarının aseton ile korunduktan sonra 2-KLG bileşiğine okside edilmesi basamaklarını gerçekleştirmeden, doğrudan ikinci basamakta elde edilen L-sorboz molekülünün paladyum katalizörlügünde, asidik koşullarda, $50^{\circ} \mathrm{C}$ sicaklık ve 6 saat süre ile okside edilmesi ile de 2-KLG molekülünün elde edilebileceği belirlenmiştir (Bommarius ve RiebelBommarius, 2004).

Prosesin son basamağı ise 2-KLG molekülünün asidik koşullarda 1sttılması ile 1,4-lakton formuna dönüşümü ve enolleşerek L-askorbik asit oluşumu işlemlerini içermektedir. Lakton formu oluşmadan önce 2-KLG molekülünün metanol ile muamele edilerek metil-2-KLG formuna dönüştürülmesinin L-askorbik asit oluşum verimini arttırdığ bildirilmiştir. Esterifikasyon ve laktonizasyon işlemleri $100^{\circ} \mathrm{C}$ sicaklikta ve $\mathrm{pH} 2$ değerinde $\mathrm{HCl}$ ve metil alkol çözeltileri kullanılarak iki saatlik reaksiyon süresince gerçekleştirilmektedir. L-askorbik asit üretimi oksijensiz ortamda $\left(\mathrm{N}_{2}\right.$ ve $\left.\mathrm{CO}_{2}\right)$ yapilmakta olup, elde edilen ürüne distilasyon, evaporasyon ve kristalizasyon işlemleri uygulandıktan sonra Laskorbik asit elde edilmektedir (Bommarius ve Riebel-Bommarius, 2004).

\section{İki Aşamalı Fermantasyon Yöntemi ile L- Askorbik Asit Üretimi}

Reichstein-Grüssner prosesinde gerekli olan yüksek enerji girdisi (sıcaklık, basınç vb.) ve çevre için zararlı kimyasalların atık olarak ortaya çıkması nedenleriyle daha az maliyet gerektiren ve daha az çevre zararı oluşturan mikrobiyal üretim basamaklarının geliştirilmesi önem kazanmıştır. Bu amaçla 1960’lı yıllarda Çin'de iki aşamalı fermantasyon yöntemi denenmiş ve bu yöntem Laskorbik asit üretimi yapan birçok firma tarafindan da uygulanmaya başlanmıştır (Zhang vd., 2010). İki basamaklı fermantasyon yöntemi "geliştirilmiş Reichstein-Grüssner prosesi" olarak nitelendirilmekte olup (Vandamme, 2016), günümüzde dünyada üretilen L-askorbik asit miktarının $\% 90$ kadarı bu yöntem ile elde edilmektedir (Yang vd., 2017). ReichsteinGrüssner prosesi ve iki aşamalı fermantasyon yöntemleri arasındaki en temel fark, Dsorbitolden fermantasyon yoluyla üretilen Lsorbozun kimyasal prosesler yerine mikrobiyal fermantasyon yoluyla 2-KLG bileşiğine dönüştürülmesidir. İki aşamalı fermantasyonun birinci aşamasında, $\mathrm{D}$-sorbitol fermente edilerek L-sorboza ve ikinci aşamasinda ise L-sorboz fermente edilerek 2-KLG bileşiğine dönüştürülmektedir (Vandamme, 2016). L-askorbik asit üretiminde kullanılan iki aşamalı fermantasyon prosesi Şekil 2'de verilmiştir.

İki aşamalı fermantasyon prosesinin ilk aşaması olan D-sorbitolün fermantasyonunda ticari üretim için daha yüksek verimle üretime olanak sağlayan $G$. oxydans mikroorganizması tercih edilmektedir (Ge vd., 2013). Gram negatif bir bakteri olan G. oxydans, Acetobacteraceae familyasında yer almaktadır. Bu mikroorganizmanın ticari açıdan önemi oksidasyon tepkimesinde rol oynayan dehidrojenaz enzimlerine (pirolokinolin kinon bağıml D-sorbitol dehidrojenaz (PQQ-SLDH), flavin adenin dinükleotide bağımlı D-sorbitol dehidrojenaz (FAD-SLDH) ve NADP bağımlı D-sorbitol dehidrojenaz (NADP-SLDH)) sahip olmasindan kaynaklanmaktadır. Endüstriyel olarak Dsorbitolden L-sorboz, D-glikozdan D-glukonik asit, 5-keto- ve 2-keto-glukonik asitler ve gliserolden dihidroksiaseton üretmek amaçlarıyla da bu mikroorganizmadan faydalanılmaktadır (Ge vd., 2013; Vandamme, 2016).

İki aşamalı fermantasyon prosesinin ikinci aşaması olan L-sorbozun fermantasyonu, 
dönüşümü gerçekleştiren ana mikroorganizma ve onun gelişimini destekleyen yardımcı mikroorganizma olmak üzere iki farklı mikroorganizma ile gerçekleştirilmektedir. Ticari üretim için ana mikroorganizma olarak Ketogulonicigenum vulgare kullanılmaktadır (Zhang vd., 2010). K. vulgare toprakta bulunan, Gram negatif ve fakültatif anaerob bir mikroorganizmadir. Bu mikroorganizmanın ticari önemi; L-sorbozu, L-askorbik asidin öncü maddesi olan 2-KLG bileşiğine dönüştürebilecek enzimlere (L-sorboz dehidrojenaz ve L-sorbozon dehidrojenaz) sahip olmasindan kaynaklanmaktadır (Huang vd., 2018). Bu mikroorganizma L-sorboz, L-guloz, Lsorboson, L-galaktoz ve L-idoz gibi bileșenleri kullanarak 2-KLG bileşiğini sentezleyebilmektedir (Zou vd., 2013). Ticari üretim için çoğunlukla L-sorboz içeren besiyeri kullanılmakta olup, besiyerine yalnızca $K$. vulgare inoküle edildiğinde mikroorganizma gelişiminin oldukça yavaş ve 2-KLG üretiminin ise düşük olduğu (Sun vd., 2018) ve üretim verimini arttırmak amaciyla Bacillus megaterium, Bacillus cereus, Bacillus subtilis ve Bacillus thuringiensis gibi yardımc1 mikroorga- nizmaların besiyeri ortamına eklendiği bildirilmiştir (Ding vd., 2014; Ma vd., 2014; Jia vd., 2017). Yapılan çalışmalar $K$. vulgare mikroorganizmasının besiyeri ortamına yalnız inoküle edilmesiyle pürin nükleotitlerini ve deoksimidilat ve folat türevlerini yetersiz sentezlemesi nedenleriyle gelişiminin yavaş olduğunu göstermiş ve besiyerine ilave dilen yardımcı suş tarafindan salgılanan proteinler, amino asitler, eritroz, eritritol ve inositol gibi endojen ve eksojen metabolitlerin ve yardımc1 suşun hücrelerinin parçalanmasından elde edilen pürin substratların $K$. vulgare mikrooorganizmasının gelişimini ve böylece 2-KLG birikimini arttırdığı bildirilmiştir (Zhang vd., 2010; Ye vd., 2014; Yang vd., 2015). 2-KLG bileşiğinin üretimi için fermantasyon genellikle $29-30^{\circ} \mathrm{C}$ sicaklıkta ve pH 6-7 değerlerinde gerçekleştirilmektedir (Zhang vd., 2010; Yang vd., 2013). Fermantasyon ile elde edilen 2-KLG molekülü ReichsteinGrüssner prosesinde de olduğu gibi esterifikasyon ve laktonizasyon işlemleri ile L-askorbik aside dönüștürülmektedir.

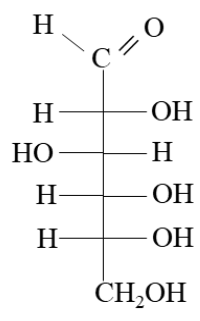

D-glikoz 1

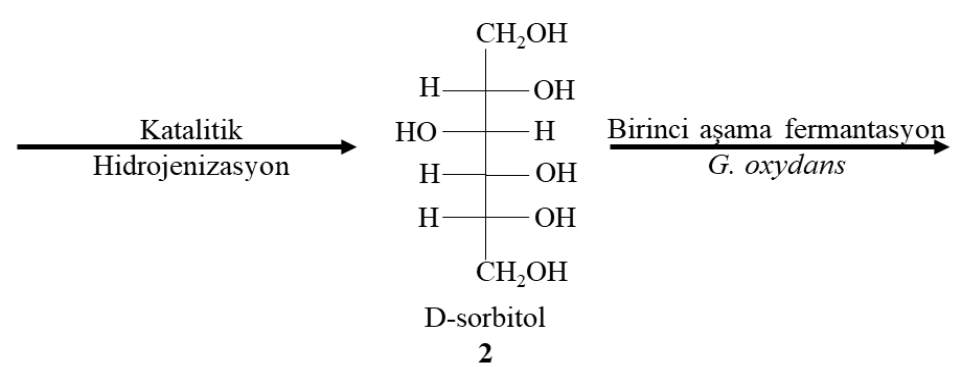

\begin{tabular}{c|c}
\multicolumn{2}{c}{$\mathrm{CH}_{2} \mathrm{OH}$} \\
& $=\mathrm{O}$ \\
$\mathrm{HO}-$ & $\mathrm{H}$ \\
$\mathrm{H}-$ & $\mathrm{OH}$ \\
$\mathrm{HO}$ & $\mathrm{H}$ \\
\hline & $\mathrm{CH}_{2} \mathrm{OH}$
\end{tabular}

L-sorboz

2
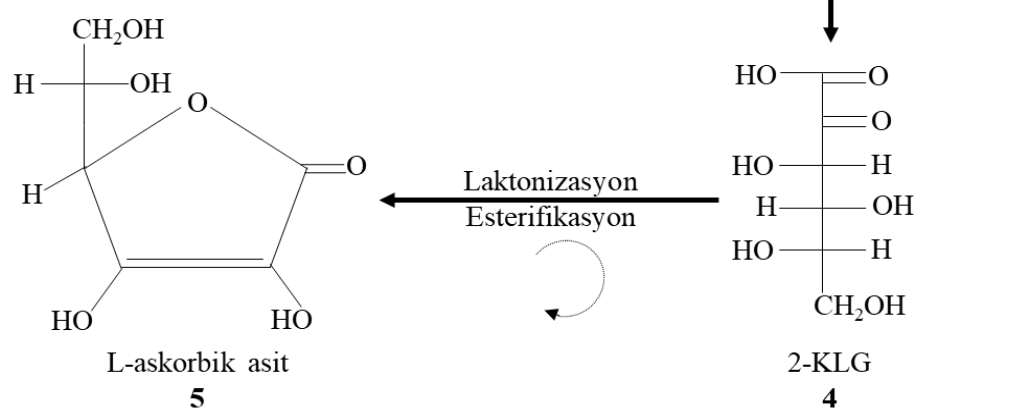

Şekil 2. L-askorbik asit üretiminde kullanılan iki aşamalı fermantasyon prosesi 


\section{SONUÇ}

D-sorbitol ve L-askorbik asit çoğunlukla bitkilerin yapısında bulunan iki bileşendir. Bu bileşenler doğal olarak bulunmalarının yanı sıra ReichsteinGrüssner prosesi veya iki aşamalı fermantasyon yöntemleri gibi kimyasal ve biyokimyasal süreçleri içeren prosesler ile de üretilerek ticari olarak satışa sunulmaktadır. Gıda, kimya, ilaç ve kozmetik sektörleri gibi birçok alanda kullanım ihtiyacı bulunan bu bileşenlerle ilgili üretim yöntemlerinin araştırılması, çalışılarak optimize edilmesi ve dünyanın farklı ülkelerinde üretilen bu katma değeri yüksek iki ticari ürünün ülkemizde de üretilmesine yönelik çalışmalarının yapılmasının önemli bir konu olduğu değerlendirilmiştir. Bu amaçla; bu bileşenlerin genel özellikleri, kullanım amaçları, sağlık üzerine etkileri ve üretim yöntemleri bu derlemede genel olarak açıklanmıştır.

\section{KAYNAKLAR}

Bhand, D.V., Patwardhan, A.V. (2015). Statistical optimization of L-ascorbic acid production by Xanthomonas campestris MTCC 2286 using sucrose as a cheap carbon source. J Biochem Technol, 6(1): 922-928.

Bommarius, A.S., Riebel-Bommarius, B.R. (2004). Biocatalysis: Fundamentals and applications. Wiley-VCH Verlag GmbH \& Co.KGaA, Weinheim, 611 pp.

Camarena, V., Wang, G. (2016). The epigenetic role of vitamin $\mathrm{C}$ in health and disease. Cell Mol Life Sci, 73(8): 1645-1658.

Canali, R., Natarelli, L., Leoni, G., Azzini, E., Comitato, R., Sancak, O., Barella, L., Virgili, F. (2014). Vitamin C supplementation modulates gene expression in peripheral blood mononuclear cells specifically upon an inflammatory stimulus: a pilot study in healthy subjects. Genes Nutr, 9(3): 390.

Covarrubias-Pinto, A., Acuña, A., Beltrán, F., Torres-Díaz, L., Castro, M. (2015). Old things new view: Ascorbic acid protects the brain in neurodegenerative disorders. Int J Mol Sci, 16(12): 28194-28217.

Deis, R.C., Kearsley, M.W. (2012). Sorbitol and mannitol. Sweeteners and Sugar Alternatives in
Food Technology (second edition). WileyBlackwell, 331-346.

del Rocío Gómez-García, M., Ochoa-Alejo, N. (2016). Predominant role of the L-galactose pathway in L-ascorbic acid biosynthesis in fruits and leaves of the Capsicum annum L. chili pepper. BrazJ Bot, 39(1): 157-168.

Delić, V., Šunić, D., Vlašić, D. (1989). Microbial reactions for the synthesis of vitamin C (Lascorbic acid). Biotechnology of vitamins, pigments and growth factors. Springer, 299-334.

Ding, M.Z., Zou, Y., Song, H., Yuan, Y.J. (2014). Metabolomic analysis of cooperative adaptation between co-cultured Bacillus cereus and Ketogulonicigenium vulgare. Plos One, 9(4): e94889.

Eitenmiller, R.R., Landen Jr, W., Ye, L. (2016). Vitamin analysis for the health and food sciences. CRC Press (second edition), $664 \mathrm{pp}$.

Fennema, O.R., Damodaran, S., Parkin, K.L. (2008). Fennema's food chemistry. CRC Press (fourth edition), $1160 \mathrm{pp}$.

García, B., Moreno, J., Iglesias, J., Melero, J.A., Morales, G. (2019). Transformation of glucose into sorbitol on Raney nickel catalysts in the absence of molecular hydrogen: sugar disproportionation vs catalytic hydrogen transfer. Top Catal, 1-9.

Ge, X., Zhao, Y., Hou, W., Zhang, W., Chen, W., Wang, J., Zhao, N., Lin, J., Wang, W., Chen, M. (2013). Complete genome sequence of the industrial strain Gluconobacter oxydans H24. Genome Announcements, 1(1): e00003-00013.

Ghosh, S., Sudha, M. (2012). A review on polyols: new frontiers for health-based bakery products. Int J Food Sci Nutr, 63(3): 372-379.

Grembecka, M. (2015a). Natural sweeteners in a human diet. Roczniki Państwowego Zakładu Higieny, 66(3): 195-202.

Grembecka, M. (2015b). Sugar alcohols-their role in the modern world of sweeteners: a review. Eur Food Res Technol, 241(1): 1-14.

Guo, X., Wang, X., Guan, J., Chen, X., Qin, Z., Mu, X., Xian, M. (2014). Selective hydrogenation 
of D-glucose to $\mathrm{D}$-sorbitol over Ru/ZSM-5 catalysts. Chinese J Catal, 35(5): 733-740.

Huang, M., Zhang, Y.H., Yao, S., Ma, D., Yu, X.D., Zhang, Q., Lyu, S.X. (2018). Antioxidant effect of glutathione on promoting 2- keto- Lgulonic acid production in vitamin $\mathrm{C}$ fermentation system. J App Microbiol, 125(5): 1383-1395.

Jia, N., Ding, M.Z., Zou, Y., Gao F., Yuan, Y.J. (2017). Comparative genomics and metabolomics analyses of the adaptation mechanism in Ketogulonicigenium vulgare-Bacillus thuringiensis consortium. Sci Rep-UK, 7(46759): 1-8.

Knight, J., Madduma-Liyanage, K., Mobley, J.A., Assimos, D.G., Holmes, R.P. (2016). Ascorbic acid intake and oxalate synthesis. Urolithiasis, 44(4): 289-297.

Kobayashi, H., Yamakoshi, Y., Hosaka, Y., Yabushita, M., Fukuoka, A. (2014). Production of sugar alcohols from real biomass by supported platinum catalyst. Catal Today, 226: 204-209.

Kowalczyk, D., Gustaw, W., Zięba, E., Lisiecki, S., Stadnik, J., Baraniak, B. (2016). Microstructure and functional properties of sorbitol-plasticized pea protein isolate emulsion films: Effect of lipid type and concentration. Food Hydrocoll, 60: 353363.

Lazaridis, P.A., Karakoulia, S., Delimitis, A., Coman, S.M., Parvulescu, V.I., Triantafyllidis, K.S. (2015). D-glucose hydrogenation/hydrogenolysis reactions on noble metal $(\mathrm{Ru}, \mathrm{Pt}) /$ activated carbon supported catalysts. Catal Today, 257: 281-290.

Ma, Q., Zou, Y., Lv, Y., Song, H., Yuan, Y.J. (2014). Comparative proteomic analysis of experimental evolution of the Bacillus cereusKetogulonicigenium vulgare co-culture. Plos One, 9(3): e91789.

Ma, X., Qiao, C., Zhang, J., Xu, J. (2018). Effect of sorbitol content on microstructure and thermal properties of chitosan films. Int J Biol Macromol, 119: 1294-1297.

Mishra, D.K., Dabbawala, A.A., Park, J.J., Jhung, S.H., Hwang, J.S. (2014). Selective hydrogenation of D-glucose to D-sorbitol over HY zeolite supported ruthenium nanoparticles catalysts. Catal Today, 232: 99-107.

Murzin, D.Y., Duque, A., Arve, K., Sifontes, V., Aho, A., Eränen, K., Salmi, T. (2015). Catalytic hydrogenation of sugars. In biomass sugars for non-fuel applications. Roy Soc Chem, 89-133.

Negahdar, L., Hausoul, P.J., Palkovits, S., Palkovits, R. (2015). Direct cleavage of sorbitol from oligosaccharides via a sequential hydrogenation-hydrolysis pathway. Appl Catal B: Environ, 166: 460-464.

Padayatty, S.J., Levine, M. (2016). Vitamin C: the known and the unknown and Goldilocks. Oral Dis, 22(6): 463-493.

Pappenberger, G., Hohmann, H.P. (2013). Industrial production of $\mathrm{L}$-ascorbic acid (vitamin C) and D-isoascorbic acid. Biotech Food and Feed Adv, 143: 143-188.

Robinson, J.M., Wadle, A.M., Reno, M.D., Kidd, R., Barrett Hinsz, S.R., Urquieta, J. (2015). Solvent-and microwave-assisted dehydrations of polyols to anhydro and dianhydro polyols. Energ Fuel, 29(10): 6529-6535.

Romero, A., Alonso, E., Sastre, Á., NietoMárquez, A. (2016). Conversion of biomass into sorbitol: cellulose hydrolysis on MCM-48 and Dglucose hydrogenation on Ru/MCM-48. Micropor Mesopor Mat, 224: 1-8.

Romero, A., Nieto-Márquez, A., Alonso, E. (2017). Bimetallic Ru: Ni/MCM-48 catalysts for the effective hydrogenation of D-glucose into sorbitol. Appl Catal A: Gen, 529: 49-59.

Sanyang, M.L., Sapuan, S.M., Jawaid, M., Ishak, M.R., Sahari, J. (2015). Effect of glycerol and sorbitol plasticizers on physical and thermal properties of sugar palm starch based films. In Proceedings of the 13th International Conference on Environment, Ecosystems and Development (EED '15), Kuala Lumpur, Malaysia, p. 157.

Sheet, B.S., Artık, N., Ayed, M.A., Abdulaziz, O.F. (2014). Some alternative sweeteners (xylitol, sorbitol, sucralose and stevia). Karaelmas Sci EngJ, 4(1): 63-70. 
Sies, H. (2014). Role of metabolic $\mathrm{H}_{2} \mathrm{O}_{2}$ generation redox signaling and oxidative stress. $J$ Biol Chem, 289(13): 8735-8741.

Sulman, E.M., Doluda, V.Y., Matveeva, V.G., Grigorev, M.E., Sulman, M.G., Bykov, A.V. (2016). Ru-containing catalysts in hydrogenation of D-glucose in flow-type microreactor. Chem Engineer Trans, 52: 673-678.

Sun, Z., Wang, R., Han, X., Xu, H., Yang, W. (2018). Enhanced 2-keto-L-gulonic acid production by applying L-sorbose-tolerant helper strain in the co-culture system. $A M B$ Express, 8(1): 30.

Thomas, L.D., Elinder, C.G., Tiselius, H.G., Wolk, A., Åkesson, A. (2013). Ascorbic acid supplements and kidney stone incidence among men: A prospective study. JAMA Intern Med, 173(5): 386-388.

Vandamme, E.J. (2016). Industrial biotechnology of vitamins, biopigments, and antioxidants. WileyVCH Verlag GmbH \& Co.KGaA, Weinheim, 578 pp.

Wang, S., Wei, W., Zhao, Y., Li, H., Li, H. (2015). $\mathrm{Ru}-\mathrm{B}$ amorphous alloy deposited on mesoporous silica nanospheres: An efficient catalyst for Dglucose hydrogenation to D-sorbitol. Catal Today, 258: 327-336.

Wheeler, G., Ishikawa, T., Pornsaksit, V., Smirnoff, N. (2015). Evolution of alternative biosynthetic pathways for vitamin C following plastid acquisition in photosynthetic eukaryotes. Elife, 4: e06369.

Yamaguchi, A., Sato, O., Mimura, N., Shirai, M. (2016). Catalytic production of sugar alcohols from lignocellulosic biomass. Catal Today, 265: 199-202.

Yang, W., Han, L., Wang, Z., Xu, H. (2013). Twohelper-strain co-culture system: a novel method for enhancement of 2-keto-L-gulonic acid production. Biotechnol Lett, 35(11): 1853-1857.
Yang, W., Liu, C., Xu, H. (2015). L-sorbose is not only a substrate for 2-keto-l-gulonic acid production in the artificial microbial ecosystem of two strains mixed fermentation. J Ind Microbiol Biot, 42(6): 897-904.

Yang, W., Han, L., Mandlaa, M., Zhang, H., Zhang, Z., Xu, H. (2017). A plate method for rapid screening of Ketogulonicigenium vulgare mutants for enhanced 2-keto-L-gulonic acid production. BrazJ Microbiol, 48(3): 397-402.

Ye, C., Wei, Z., Nan, X., Liming, L. (2014). Metabolic model reconstruction and analysis of an artificial microbial ecosystem for vitamin C production. J Biotechnol, 182: 61-67.

Zada, B., Chen, M., Chen, C., Yan, L., Xu, Q., Li, W., Guo, Q., Fu, Y. (2017). Recent advances in catalytic production of sugar alcohols and their applications. Sci China Chem, 60(7): 853-869.

Zhang, J., Li, J.B., Wu, S.B., Liu, Y. (2013). Advances in the catalytic production and utilization of sorbitol. Ind Engineer Chem Res, 52(34): 11799-11815.

Zhang, J., Liu, J., Shi, Z., Liu, L., Chen, J. (2010). Manipulation of B. megaterium growth for efficient 2-KLG production by K. vulgare. Process Biochem, 45(4): 602-606.

Zhang, X., Durndell, L.J., Isaacs, M.A., Parlett, C.M., Lee, A.F., Wilson, K. (2016). Platinumcatalyzed aqueous-phase hydrogenation of $\mathrm{D}$ glucose to D-sorbitol. ACS Catal, 6(11): 74097417.

Zhou, J., Du, G., Chen, J. (2012). Metabolic engineering of microorganisms for vitamin C production. Reprogramming Microbial Metabolic Pathways, Springer, 241-259.

Zou, W., Liu, L., Chen, J. (2013). Structure, mechanism and regulation of an artificial microbial ecosystem for vitamin $\mathrm{C}$ production. Crit Rev Microbiol, 39(3): 247-255. 